\title{
Scores for Effective Forest Conservation: A Village-to- Village Approach
}

\begin{abstract}
R. K. Pokharel ${ }^{1}$ and H. O. Larsen ${ }^{2}$
Community forestry in Nepal strives for forest conservation and sustainable forest management. Evaluating progress towards this end requires periodic measurements, and currently there are no standard tools for undertaking evaluations in a participatory way. The purpose of this paper is to suggest a standardized way for measuring effective forest conservation through the use of locally set scores. A village-to-village approach was used to assign scores on criteria and indicators developed earlier for forest conservation. A total of eight small meetings with forest users were conducted to elicit their perspectives and quantify their progress towards conservation by means of scores. For the 14 criteria specified, local forest users assigned higher scores to four criteria: two for social and one each for socio-economic and environmental spheres. This paper argues that a score of 59 or above is an effective cut off for determining "effective" forest conservation.
\end{abstract}

Keywords: Community forest, criteria, forest management, indicator, village,

$\mathbf{T}$ his paper attempts to address the issue about how to compare the performance of community forest management in terms of effective forest conservation. We use the criteria and indicators developed by Pokharel and Larsen (2007) as a basis for assigning scores to evaluate effective forest conservation. The criteria and indicators were developed to determine whether CFUGs conserved forests effectively. Indeed, effective forest conservation is expected to lead to a sustainable forest management, the ultimate goal of community forestry program (Acharya, 2002), and that of Nepal's forest policy (HMG, 2000). The government has instituted a forest conservation award at the national level to recognize and encourage CFUGs to manage their forests sustainably. Every year, the government recognizes the three most successful CFUGs according to a set of guidelines (MFSC, 2004) for this award. As one of the foundations of Nepal's community forestry is the participation of local forest users in the planning, implementation and general decision making (HMG, 2000; SpringateBaginski et al., 2003), arguably, the local perspectives on the performance indicators should also be accorded due recognition. In line with this thinking, some exploration of local perspectives have started (Smith et al., 2003; Shrestha and Khanal, 2004; Pokharel and Larsen, 2007; Pokharel and Suvedi, 2007). However, none of the studies of comparison, proposed so far, have incorporated local priorities. Local scoring of criteria and indicators is one way of providing some means for comparison that will take into account the local perspectives in the evaluation. A set of agreed criteria will furthermore allow evaluation to be highly transparent. Transparency is important to motivate forest users, because in Nepal, people often manipulate things in favor of afno manche (ones own people, friends or relatives) once in power. In this context, this paper is expected to contribute to the development of a transparent evaluation system for Nepal's community forests. Furthermore, it is also expected to assist the villagers to examine the effectiveness of their forest conservation.

\section{Materials and Methods}

This paper uses the criteria and indicators developed by Pokharel and Larsen (2007) for evaluating effective forest conservation. Scores are assigned by local people on their assessment of the criteria and indicators developed by the CFUGs they visit. We chose village to village approach as this permits researchers to cross check the information, and to acquire the perspectives from males, females, and from different castes and so on, to foster a feeling of local ownership of the process. Village to village approach requires visiting rural areas and offering

\footnotetext{
${ }^{1}$ Institute of Forestry Tribhuvan University, PO Box 43, Pokhara, Nepal; e-mail: ridishp@gmail.com

${ }^{2}$ Forest \& Landscape, Copenhagen University, Denmark; e-mail: hol@life.ku.dk
} 
local people a chance to reflect on and analyze their experiences. In this study, we used a village-to-village approach by visiting CFUGs and holding 20-30 minutes informal discussions for assigning the score along the given criteria and indicators.

A total of eight small group meetings were conducted with CFUG members separately (one meeting each in Jaykot, Kankali, Rani, and Malatimahila CFUGs and two meetings each in Thanimia and Simalchaur CFUGs). Since only one individual attended the first meeting of Thanimai and Simalchaur CFUGs, we decided to conduct additional meetings with these CFUGs. Locating individuals interested in participating in the discussion was relatively easy as good rapport had been nurtured through earlier visits and the researcher was also familiar with the local situation. We directly approached forest users for small group meetings since the first author was familiar with the local situation and CFUGs. We first contacted a random individual in the field and then requested him or her to invite a few more individuals to a small group meeting. The meeting was conducted at chautaras (communal meeting/resting places under specific tree shades in a village) or at one of the respondents' home, depending on the convenience of the respondents. The data was recorded in September 2006.

\section{Results and discussions}

The meetings were conducted with an air of informal ambience. Working together with small groups as indicated by Schusler et al (2003) provided an opportunity for dialog among participants. At each meeting, we explained the purpose and objective of our visit and about the criteria and indicators. Then, with a flip chart, the list of the criteria and indicators was expounded. We invited the participants to assign a score, between 1 and 10, for each application of the criterion and indicator in forest conservation in their own situations. Ascribing a quantitative number or value for each of the criteria and indicators was not easy for forest users, and at first they could hardly agree on a common, assessed value. After discussing among themselves they finally reached consensus. So by applying the criteria and indicators to their own situations and assigning the scores accordingly, they were able to compare the effectiveness of forest conservation for different CFUGs. Each score was recorded onto the flip chart and read aloud so everyone could confirm what number was agreed on for a given set of criterion and indicator. After the recitation of the scores, the participants sometimes revised the scores for some criteria or indicators.

Table 1 lists the average scores and adjusted scores for the given criteria and indicators used in this study. The average scores and the adjusted scores are the sum of all scores divided by the number of meetings and the final score for each criterion and indicator, respectively. We computed the average score as the sum of the scores for each criterion and indicator assigned by local people divided by number of meetings. Similarly, we computed the adjusted score by converting the total score into 100 .

Pokharel and Larsen (2007) identified two types of indicators - cumulative and non-cumulative. Cumulative indicators meant more than one indicator could be assigned to a given CFUG, but only one non-cumulative indicator could be assigned. As values for criteria could be assigned from 1 to 10 to calculate the total score of a CFUG indicator, values proportionate to the value of the relevant criterion are summed. For example, if an area at the time of handover to a CFUG was naked or barren the score value would be 9 . When adjusted for the relative importance of the criterion, this value would be 7.63 out of 10 , and this score is adjusted to 6.86 . For cumulative indicators, the maximum total value that could be assigned was the value of the corresponding criterion. The indicator values assigned are reduced proportionately. For example, if community forest management had resulted in increased greenery and improved water quality, a score of 15.51 was assigned. The average criterion score was 8.38 , the total assigned score of indicators was 32.25 , and the adjusted score, therefore, came to be 4.03 . The maximum total value of a CFUG was 94.06, while the minimum was 23.84, with the average score being 58.95 .

The results indicate that local forest users perceived attendance of all users in the general assembly and development of healthy environment as the most important inputs for sustainable community forest management, whereas the size of the CFUG fund and composition of the forest management committee were perceived as less important. The criteria and scores indicate that community forest users envision conservation as requiring a holistic perspective, assigning high scores to criteria on environmental, social and socio-economic spheres such as the use of CFUG funds. 
Table 1: Average score on criteria and indicators as perceived by local people

\begin{tabular}{|c|c|c|c|}
\hline Indicators & $\begin{array}{c}\text { Average } \\
\text { criteria score }\end{array}$ & $\begin{array}{c}\text { Average } \\
\text { indicator Score }\end{array}$ & Adjusted score \\
\hline Attendance of all users in general assembly* & 8.38 & & 7.76 \\
\hline Up to $50 \%$ & & 5.13 & 3.95 \\
\hline $51-75 \%$ & & 7.63 & 5.89 \\
\hline Above $75 \%$ & & 9.38 & 7.21 \\
\hline Development of healthy environment & 8.38 & & 7.76 \\
\hline Increased greenery & & 8.63 & 2.14 \\
\hline Increasing availability of water source & & 8.38 & 2.07 \\
\hline Reduced soil erosion/landslides & & 8.38 & 2.07 \\
\hline Improved drinking water quality & & 6.88 & 1.70 \\
\hline Forest management practices & 8.25 & & 7.64 \\
\hline Block division in the forests & & 8.75 & 2.93 \\
\hline Construction of fire line & & 7.63 & 2.55 \\
\hline Regular silvicultural operation & & 7.5 & 2.51 \\
\hline State of forests at time of evaluation & 8.25 & & 7.64 \\
\hline Presence of good shape trees & & 8.75 & 1.86 \\
\hline Reappearance of spp. that were lost & & 8.25 & 1.75 \\
\hline Appearance of wildlife & & 8 & 1.70 \\
\hline Community access to fuel wood & & 7.88 & 1.67 \\
\hline Financial transparency of CFUG committee & 8.13 & & 7.53 \\
\hline Presentation of financial report in $G A^{* *}$ & & 8.75 & 2.14 \\
\hline Access of all users to financial report & & 8.75 & 2.14 \\
\hline Presentation of financial report in $\mathrm{PH}$ & & 8.13 & 1.99 \\
\hline Formation of sub-committee for FM & & 7 & 1.71 \\
\hline Use of CFUG funds & 8 & & 7.41 \\
\hline Community development works & & 7.88 & 1.56 \\
\hline Forest improvement activity & & 7.88 & 1.56 \\
\hline Self-employment skill development & & 7.63 & 1.51 \\
\hline Literacy programs for forest users & & 6.13 & 1.21 \\
\hline Soft loan for income generating & & 5.63 & 1.12 \\
\hline Proportion of women in general assembly* & 8 & & 7.41 \\
\hline Up to $25 \%$ & & 4.88 & 3.55 \\
\hline $26-50 \%$ & & 7.25 & 5.33 \\
\hline $51-75 \%$ & & 7.88 & 5.77 \\
\hline Above $75 \%$ & & 8.63 & 6.37 \\
\hline Performance of CFUG committee & 7.75 & & 7.18 \\
\hline Preparation of yearly CFUG report & & 8.75 & 1.47 \\
\hline Meetings are conducted regularly & & 8.63 & 1.45 \\
\hline Effective information sharing & & 8.13 & 1.37 \\
\hline Formation of sub-committee for MA & & 8 & 1.35 \\
\hline Assessment of users' needs & & 8 & 1.35 \\
\hline State of forest before hand over* & 7.63 & & 7.07 \\
\hline Naked and barren hills & & 9 & 6.36 \\
\hline Plantation areas & & 7.25 & 5.09 \\
\hline Natural forests & & 6.5 & 4.59 \\
\hline Forest protection system* & 7.63 & & 7.07 \\
\hline Self-disciplines & & 9 & 6.36 \\
\hline Users on rotational basis & & 7.38 & 5.16 \\
\hline Hiring forest watchers & & 5 & 3.53 \\
\hline Awareness of forest importance among users & 7.38 & & 6.84 \\
\hline CFUG organizes tree planting activity & & 7.25 & 2.58 \\
\hline Illegal cutting from forest is reduced & & 6.88 & 2.45 \\
\hline Informal class on forestry issues & & 5.5 & 1.96 \\
\hline Forest products distribution system* & 7 & & 6.48 \\
\hline Equity - needy get more & & 7.75 & 4.98 \\
\hline Equal - all get equal share & & 5 & 3.24 \\
\hline CFUG fund size* & 6.88 & & 6.37 \\
\hline Below Nrs15,000 & & 4.88 & 3.05 \\
\hline Nrs15,000 - 24,999 & & 6.13 & 3.88 \\
\hline Nrs25,000 - 49,000 & & 7.25 & 4.58 \\
\hline Nrs50,000 and above & & 8.63 & 5.47 \\
\hline Composition of CFUG committee* & 6.75 & & 6.25 \\
\hline Proportional representation of sexes & & 8.5 & 5.31 \\
\hline Equal ratio of male and female & & 7.88 & 4.87 \\
\hline $50 \%$ or more are women & & 7.25 & 4.50 \\
\hline Domination of one group & & 4 & 2.50 \\
\hline Only men & & 3.13 & 1.93 \\
\hline
\end{tabular}

*Indicators under the criteria are non-cumulative

**PH meaning public hearing; FM meaning financial monitoring; GA meaning general assembly; MA meaning monitoring activities 
Interestingly, the participants were reluctant to assign full scores to neither criteria nor indicators. This may be the acculturation spill over from experiences with the Nepalese education system wherein students are rarely awarded a hundred per cent score on a test. This tendency introduces methodological problems for the interpretation of the evaluation.

Generally, criteria are assigned higher scores when they reflect current problems, for example, with regards to the distribution of forest products and gender inequality (Agrawal, 2001; Malla et al., 2003), financial transparency, and environmental aspects. The community forestry program is regarded as environmentally beneficial (Gautam et al., 2002; Karna et al., 2004).

At this point an evaluation of CFUGs according to the presented criteria and indicators would yield comparative quantitative information about the success of forest conservation. We propose that, for now, CFUGs earning average or more of the possible score (score with 59 and higher) be designated as demonstrating "effective" forest conservation.

The number of CFUGs visited for this study was small. To develop a national list of criteria and indicators truly representing the views of forest users would call for more observations. In terms of methods, the village to village visit approach was found to be effective for fostering interaction with the local people and for gathering information. This approach allowed us to observe a village, get a sense of what was going on, and to compare the information with field reality. Moreover, it was relatively easy to establish rapport with local people by demonstrating respect and interest. Indeed, local people felt happy when their work was acclaimed and cited as one of the reasons for choosing the area. The village to village approach requires building trust with local people which is not an easy task. Several visits and positive discussions regarding the local work would facilitate the build-up of trust.

\section{Conclusions}

Developing and scoring criteria and indicators for forest conservation assists local people to evaluate their own performances. They can use it as a transparent tool to evaluate themselves independently - whereas central evaluations are perceived to be opaque and often invite controversy and illegitimacy. This study has demonstrated that forest users can develop and score criteria and indicators for forest conservation, and that their perceptions of conservation are more holistic than narrow. Some conceptual challenges were encountered regarding the reluctance to assign absolute maximum and minimum scores of 100 or 0 to indicators. In general, though, this experience has shown that forest users were able to discuss the evaluation of forest management competently and that the village to village visit approach was effective for gathering reliable information.

\section{References}

Acharya, K. P. 2002. Twenty five years of community forestry in Nepal, International Forestry Review 4 (2): $149-156$.

Agrawal, B. 2001. Participatory exclusions, community forestry, and gender: An analysis for South Asia and a conceptual framework, World Development 29: 1623 - 1648.

Springate-Baginski, O., Dev, O. P., Yadav, N. P. and Soussan, J. 2003. Community forestry management in the Middle Hills of Nepal: the changing context, Journal of Forests and Livelihoods 3 (1): $5-20$.

Gautam, A.P., Webb, E.L., and Elumnoh, A. 2002. GIS assessment of land use/land cover changes associated with community forestry implementation in the Middle Hills of Nepal, Mountain Research and Development 22: 63 - 69.

His Majesty's Government of Nepal (HMG) 2000. Revised Forestry Sector Policy, HMG, Ministry of Forests and Soil Conservation, Kathmandu/ Nepal

Karna, B.K., Gyawali, S. and Karmacharya, M.B. 2004. Forest condition change: Evidence from five revisited community forests. In K. R. Kanel, P. Mathema, B. R. Kanel, D. R. Niraula and M. Gautam (eds.), Twenty five years of community forestry, Proceedings of the fourth national workshop on community forestry, Community Forest Division, Department of Forests, Kathmandu: 118 - 123.

Malla, Y.B., Neupane, H.R., and Branney, P. 2003. Why aren't poor people benefiting more from community forestry? Journal of Forests and Livelihoods 3 (1): 78 - 93. 
MFSC, 2004. 2059 salko ganeshman singh bansanrakechan puraskar 2054 kolagi 059/7/13ko chbalfalbata chbanaut samitile prastab gareko abedan faram (proposed application guidelines 2059 for Ganesh Man Singh forest conservation award 2054 by selection committee meeting held on 2059/7/13), Ministry of Forests and Soil Conservation, Kathmandu.

Pokharel, Ridish K. and Larsen, Helle O. 2007. Local versus official criteria and indicators for evaluating community forest management, Forestry: An International Journal of Forest Research 80 (2): 183 $-192$.

Pokharel, Ridish K. and Suvedi, Murari 2007. Indicators for measuring the success of Nepal's community forestry program: A local perspective, Human Ecology Review 14 (1): 68 - 75.

Schusler, T.M., Decker, D.J. And Pfeffer, M.J. 2003. Social learning for collaborative natural resource management, Society and Natural Resources 16 (4): $309-326$.

Shrestha, K. and Khanal, P.N. 2004 Forest Certification: Experiences from Parbat District. Seed Tree Nepal, Integrated Human Ecology Project, Parbat. UNDP/GEF Small grants Programme, Kathmandu.

Smith, P.D., Chhetri, B.B.K. and Regmi, B. 2003 Meeting the needs of Nepal's poor: creating local criteria and indicators of community forestry. Journal of Forestry 101 (5): $24-30$. 